\title{
Passive cooling in the restoration of historic buildings
}

\author{
L. Capuano, E. Laurini \& P. De Berardinis \\ Department of Building, Civil Engineering-Architecture \\ and Environment, University of L'Aquila, Italy
}

\begin{abstract}
Ancient villages are one of the most fascinating expressions of the Italian historical heritage. They are unique in their culture, landscape, and architecture, representing a huge potential for the socio-economic recovery of remote in lands, which tend to be exposed to the risk of abandonment. In order to achieve a successful recovery of these villages, the local critical climatic factors must be analyzed with a holistic approach, rather than focusing on single aspects. For instance, an integration of sun exposure and natural ventilation analyses, allows to define comprehensive methodology which can help predicting the impact of these climatic parameters on the buildings. Often, the spontaneous layout of the urban fabric, typical of many villages, results in critical conditions during both the summer and the winter time and these conditions must be analyzed from all angles in order to be properly understood. For instance, optimal analyses require, at first, the elaboration of a three-dimensional model of an entire village; then, a check and verification tool for the main climatic parameters can be developed. At the Italian latitudes, during winter time objects have a greater shadow field at midday. During summer time instead, the shadows have a shorter extent when the sun is at its zenith, whilst they reach their maximum at sunrise and sunset. It is well to outline what are the areas at risk from overheating in the summer and which are in perpetual shade in winter. Based on these solar analysis observations it is possible to detect and discriminate those areas that in the summer may be more exposed to sunrays and experience overheating, from those that during winter are in complete shade. Also, a combined analysis of dynamic shadow projections and trail winds allows to define the relationship between site, sunshine and wind. As very often the local climate can have very variable wind conditions at different times of the year, a creation of a passive cooling system is possible through the identification of thermal energy
\end{abstract}


storage areas, appropriate materials, surface treatments, and optimal design strategies for wind ventilation. We propose to redirect wind flows in specific areas through architectural devices which favor the effect of natural ventilation and help cooling the buildings down.

This paper presents a series of optimal design solutions and intervention strategies aiming to mitigate the risks of weathering for those buildings that are potentially affected by critical climatic conditions with a minimal impact on the existing environmental and morphological context.

Keywords: passive cooling, historical buildings, thermal storage, climate.

\section{Introduction}

Rosciolo is a small town of the municipality of Magliano dei Marsi, located in the province of L'Aquila, Abruzzo, Italy. The village is located on a hill at 900 meters of altitude, in a panoramic position above the Porclaneta Valley, between the western slopes of Mount Carce and the foothill of Mount Velino.

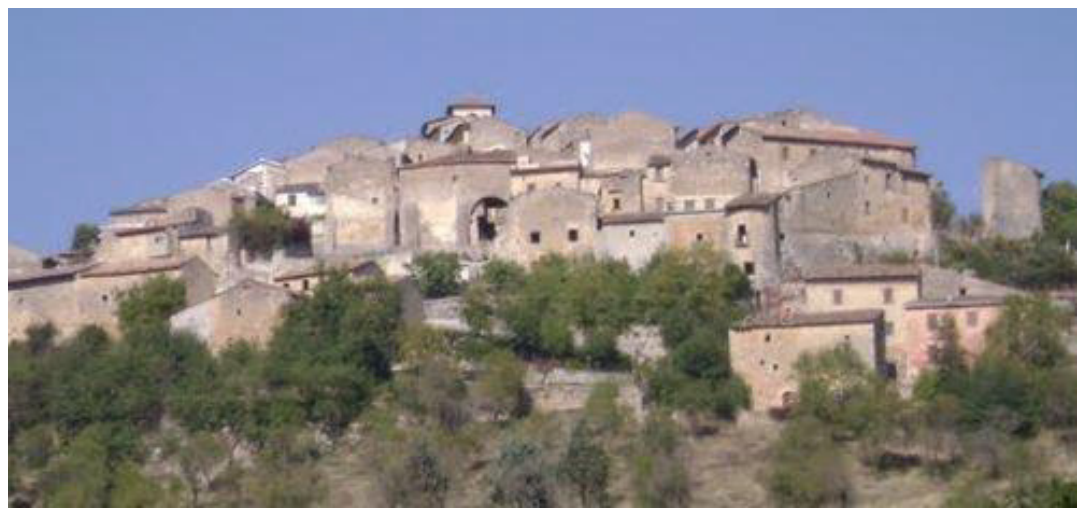

Figure 1: The village of Rosciolo dei Marsi in the municipality of Magliano dei Marsi.

The hill is elongated in the southeast-northwest axis and the majority of the village appears to be almost entirely built along the crest, with localized urban voids due partial collapses that have occurred over time.

The construction consists primarily of two and three-story buildings, with some complexes that reach up to four stories and which are likely to be of noble origin. Repeated maintenance and development of individual buildings has led to a partial alteration of the homogeneity of both the urban layout and village identity. The practicability is mostly pedestrian, while driveways are all tangential to the building complexes. As for the demographics, the town hall records document the status and the exodus of the entire population of Magliano dei Marsi, including its two hamlets Rosciolo and Marano. The Diocesan archive instead provides demographic information only from 1887 to 1899 [1-4]. It is reported that the population of Rosciolo on December 31, 1868 accounted for 109 individuals. 


\section{Territorial climate profiles}

The purpose of this research is to establish a climate profile at a local geographic level which takes into account of both ventilation and spatial analyses, thus allowing to define proper design solutions in line with the orographic settings.

The site climate profiling proposed here aimed to evaluate the weather issues related to sun exposure and winds regimes, and how the orographic conditions of the site may impact the local climate..

- Climatic analyses were performed according to the reference values of the UNI 10349: "Heating and cooling of buildings - Climatic data", reported for each provincial capital;

- $\quad$ average speed and prevailing wind direction;

- monthly average of direct and diffuse radiation;

- monthly average temperatures;

- maximum summer temperature;

- maximum relative humidity;

- minimum relative humidity.

\subsection{Ventilation analysis}

Downstream of buildings invested by the wind they create a calm wind zones. These areas determine, on the surfaces of buildings and grounds, a reduction of wind speed, which has effects on both the well-being of those who carry out activities in outer space, both on the microclimate of the interior. A thorough massing orientation must consider existing site conditions, which sometimes can be advantageous. For instance wind speeds are faster at greater heights (i.e. the hill crest), whereas reduced wind speeds occur downstream. This peculiar downstream condition may favour outdoor activities and also influence the microclimate of the interior.

A comprehensive virtual three-dimensional model was created for assessing the climatic and environmental parameters of the entire village. The WinAir Ecotect software was adopted to perform wind analyses considering regional as well as local conditions, as they both may impact the indoor ventilation regimes. We analyzed the prevailing wind direction, the maximum and minimum temperature, the minimum and maximum relative humidity, the relative humidity, with the best and worst conditions (i.e. solstices and equinoxes), over a 12-month time frame. Then, we created the anemometric diagrams to calibrate our model with real-world data.

The prevailing winds blow mostly from the southwest during the winter and from east during the summer east. However, the latter are largely shielded by the adjacent Mount Velino slopes and have a minor impact on the village. 

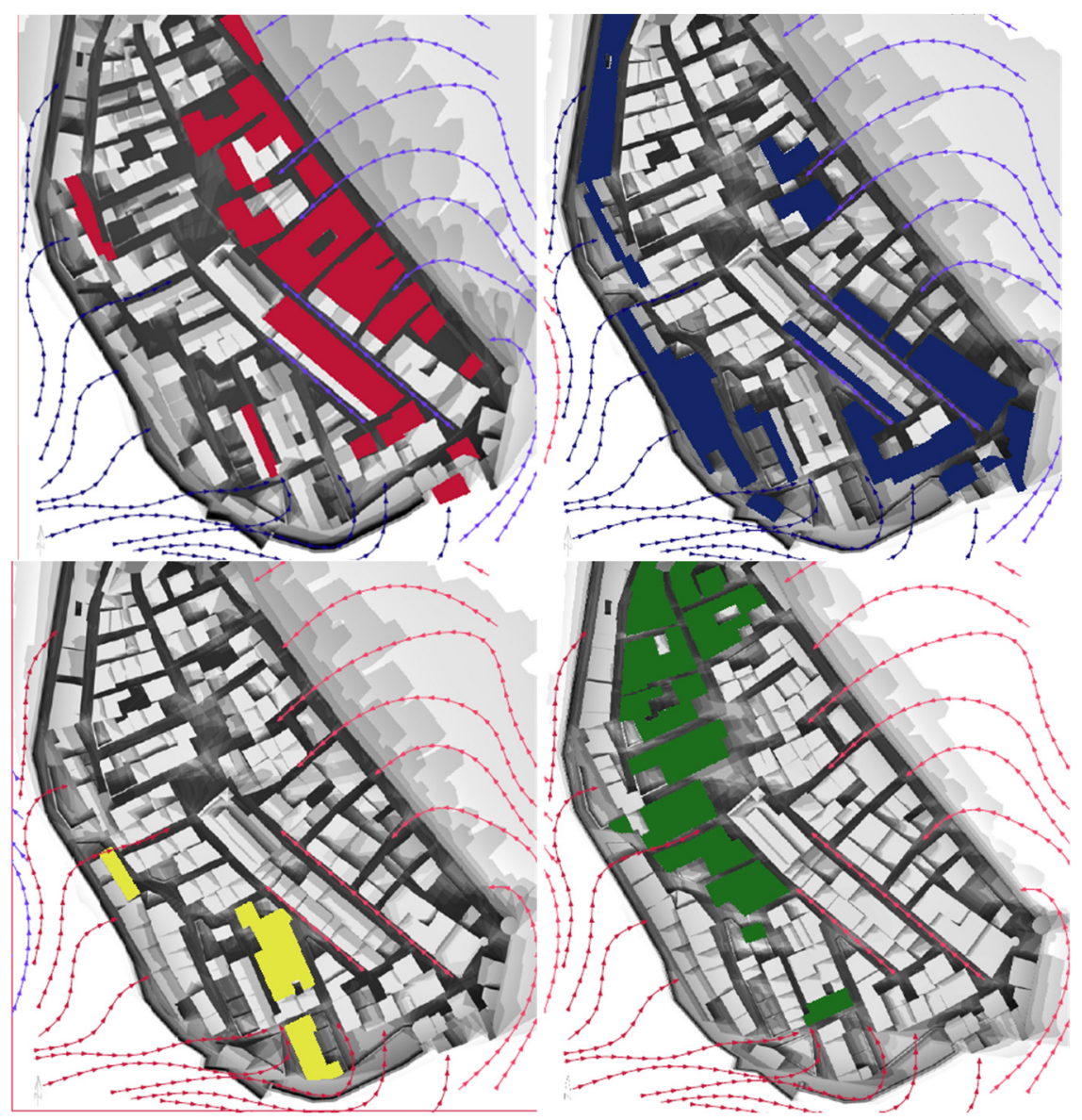

$\mathrm{Hrs}$

$\mathrm{C}^{\circ}$

$\%$

$\%$

\begin{tabular}{|l|l|l|l|l|}
\hline $1126+$ & $45+$ & $95+$ & $95+$ \\
\hline 1013 & 40 & 85 & 85 \\
\hline 900 & 35 & 75 & 75 \\
\hline 788 & 30 & 65 & 65 \\
\hline 675 & 25 & 55 & 55 \\
\hline 563 & & 20 & 45 & 45 \\
\hline 450 & 15 & 35 & 35 \\
\hline 337 & & 25 & 25 \\
\hline 225 & 5 & 15 & 15 \\
\hline$<112$ & $<$ & 5 & $<5$ & $<5$ \\
\hline
\end{tabular}

Figure 2: Wind flows diagram. 


\subsection{Solar analysis}

Regional and local solar analyses were carried out using the Ecotect software, which allows to simulate the orbital path of the sun relative to the Earth motion. This information is key for understanding how sun exposure and shading conditions of a specific area vary during the day and throughout the year.

The sunshine and shading levels are dramatically different in the two most extreme seasons of the year, due to different solar path dynamics and daylight durations. At the Italian latitudes, objects have a greater shadow field at midday during the winter and a shorter extent during the summer with their maximum at sunrise and sunset.

This basic observation helped us defining the areas with higher overheating risks in summer and in perpetual shadow during the winter.

Also, a stereographic diagram was created to determine how the sun exposure of an area is affected by the shading of adjacent buildings, existing vegetation, and orographic reliefs.

An integration of these analyses allowed to evaluate the potential for the installation of either photovoltaic or solar thermal panels.

In the case of Rosciolo we have identified four areas, ranked from excellent to poor, of which those having west-facing flaps being the best in terms of sun exposure.

\subsection{Open space analyses}

The combined analysis of the dynamics of the shadows and windy trails, carried out by overlaying the shadow projections and wake nuclei generated in the horizontal plane, allows to establish the relationship between site, sunshine and wind. The overlap is punctual, both in time and space, and it is therefore related to a specific shading zone and to a prevailing wind direction. The analysis resulted in four possible combinations:

- $\quad$ sunny area;

- $\quad$ sunny area and windy wake;

- $\quad$ shaded area and breezy;

- $\quad$ shaded area and windy wake.

This type of analysis can be useful to define the destination of use of the outdoor spaces depending on the users' preferences and natural vocation. The main purpose of this type of analysis is that of limiting the stress caused by the climate and improve the outdoors life quality.

\section{The influence of the climate on the conformation of the build}

The way a building relates to the physical structure of the landscape is by following its variations and creating a relationship between the empty and the full, with typical perspective views and rhythms aggregation in harmony with the local physiographic relief. This urban layout appears very compact and bumpy and it is typical of medieval settlements. 
The historic central neighbourhood of Rosciolo is based on a cardo-decumanus confined by a double wall masonry with an elliptical geometry.

The inner wall is defined by a series of wall-houses locally interrupted by village accesses consisting of arched houses; on the other hand, the outside is limited by an outer annular wall that extends along the perimeter of the building and from which emerge watchtowers emerge. The conditioning imposed by the hilly terrain and the need for protection against the weather are some of the factors that determine the size and conformation of the buildings of Rosciolo. From the wind flow analysis showed in Figure 2 it is clear that the village has a net ventilation closure, due to the development of the outer wall and the front of the cold winds, while on the opposite side there is an evident fragmentation due to many inputs represented by opened arched houses that allow wind inflows at moderately warm temperatures.

\section{Transformability and environmental value}

The identity of another architectural organism is the temporal stratification of successive interventions and needs knowledge of the building on which to intervene.

The answer to "what to recover?" is a function of the different values that can be assigned from time to time by finding documentation or historically established image [5].

Only when it is established with "what" preserve, then it will be possible to define the context in which the "how to recover" makes the most of the potential offered by the degree of transformation of these artefacts. This degree may be:

- zero;

- minimum;

- partial;

- maximum

A design that is compared to the "convertibility" offers the possibility of a continuous monitoring and the verification of design choices, which will be made within consistent rules defined by a level of transformation of a hierarchical system (e.g. the degree of transformability of the bodies is a function of the transformability of the weights of the individual components, one of the fabrics, of the bodies and consequently of building components) and interdependent (transformability to higher scale requires all lower scales, but not contrary).

So the higher the convertibility, the greater will be the tampering of original material and consequently the improvement of performance levels.

The design methodologies are oriented to the recovery of historical buildings, the historical and temporal dimension in which the architectural organisms lie, as well as the dynamic modification of the boundary conditions and the level of human activity, are more reference element. Also, although environmental value overall result of immediate perception, its protection, as non-renewable resource, must be reported to the overall shape of constructed values and its link with the topography or more generally with the natural environment. 
This can be achieved through the identification of the morphological characteristics and typological values (e.g. basic building types, laws of growth and transformation, etc.).

Therefore, the proposition of use of transformations that can lead to substantial changes in the system original city, the traditional type of building, the functional relationship with the structure of settlements, must be carefully assessed.

Much of the protection of environmental values, therefore lies in the protection of the coherence values of the entire old town centre system.

The transformation, in view of the active preservation, cannot imply a particular reference to those that have their own content of the climatic context. As a matter of fact, although the climate has never been among the most significant factors leading to the formation of a village, it is recorded in the evolution of the building type and conformation of the urban fabric [6]. Today any controlled transformation intervention must take this into consideration along with all the climatic conditions. The intervention of revisiting the "arch house" and its location proposes a virtuous path of interpretation of climate data through which critical issues can be solved without affecting the welfare conditions that characterize the historic town.

\section{Design and modern interpretation of the arched house}

To guarantee a long life to old town it is necessary an insightful and flexible use of the design to resolve issues ranging from treatment surfaces to choose a suitable plant equipment, to remove incongruous additions to the gaps integrations.

Demolition, reconstruction, consolidation, restoration and conservation are not abstract and rigid opposed categories, but the key through the project activity is expressed, is analysis the pre-existence flows naturally in a mature and purposeful synthesis.

As a matter of fact we will need just only instrument able to respond to the heterogeneity and the specificity of the different contextual situations.

Based on knowledge of the historical building, as material culture $[6,7]$, interpretation of architectural space and entrusted to the designer's ability, we must be aware of the relationship between analysis and project and design and construction.

Maximize the value of analytic knowledge and pinpoint the areas that characterize the architecture and the urban space, is part of the necessary choices, to define the limits of the transformation that the work will suffer. Any kind of conservation involves distinct stages of the research, from the understanding of the monument as a document, to the implementation of the decisions necessary to counteract degradation.

Highlight or exclude any of this stage it is against the idea of conservation; it is utopian thinking of preservation without appropriate recovery actions.

The effort to define innovative criteria for building restoration must be up to the scale of construction and technology by offering a careful recovery of the knowledge of this field. 
We must establish values significant for historic structure, sufficient to enable the recovery of it according to the parameters corresponding to different scales: the urban scale, the scale of the block or the urban sector, the scale of the single architectural work [8-10]. Every cultural object has the values to be communicated, so this should be valid also for the historic construction.

Historically, the old town are related to the housing needs which it would have been greater if the local families had decide to extend or modify their existing house.

Despite the continuous metamorphosis, declined over time with elevations, additions and modifications that were physical representations of buildings on vitality, the memory will remain in the extraordinary stratification and beauty of the old town through which we can appreciate and understand the dynamics.

The identification of critical weather leads to the definition, in the design phase, intervention strategies. We evaluate possible solutions related to problems and levels of critical environmental climate, paying attention to the morphological and environmental constraints of the existent. The site-specific analysis shows the presence of three homogeneous areas identified as the best area for the recovery, the one facing west near the wall.

Combining the thermal storage areas with the use of carefully chosen materials, surface treatment and the realization of a screen that re-reading of the arched house, it is possible reduce the passage of cold drafts, encouraging the environmental well-being by not obstruct the sun exposure in the winter but reducing it in the summer.

Below there is a three-dimensional model that shows a modern reinterpretation of the arched house with the insertion of a horizontal element that connects two buildings. The principal front on the open passage creates a genuine "arc".

The intervention proposes the typical construction type of the inserting place in a tacit way in to existing houses arc system.

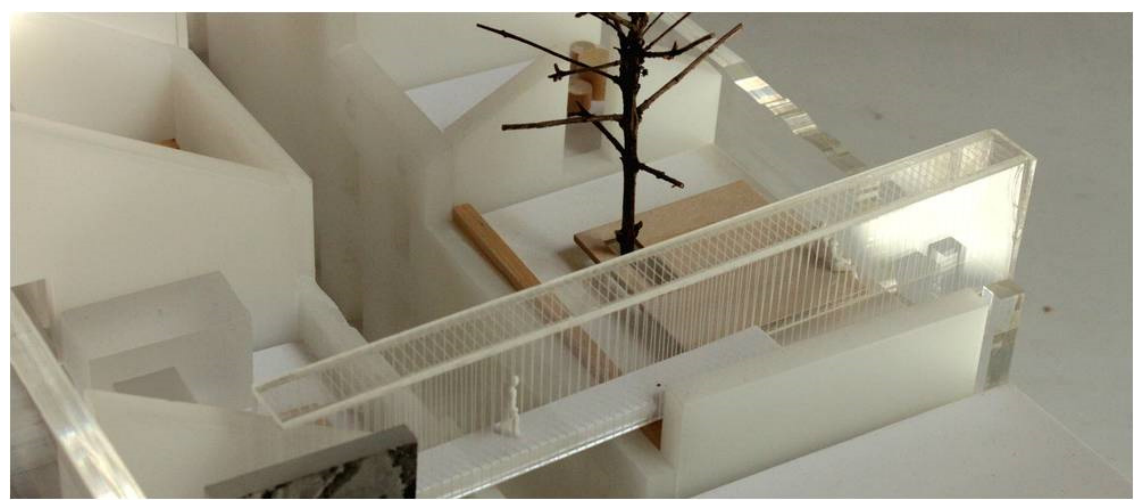

Figure 3: $\quad$ Project proposal. 


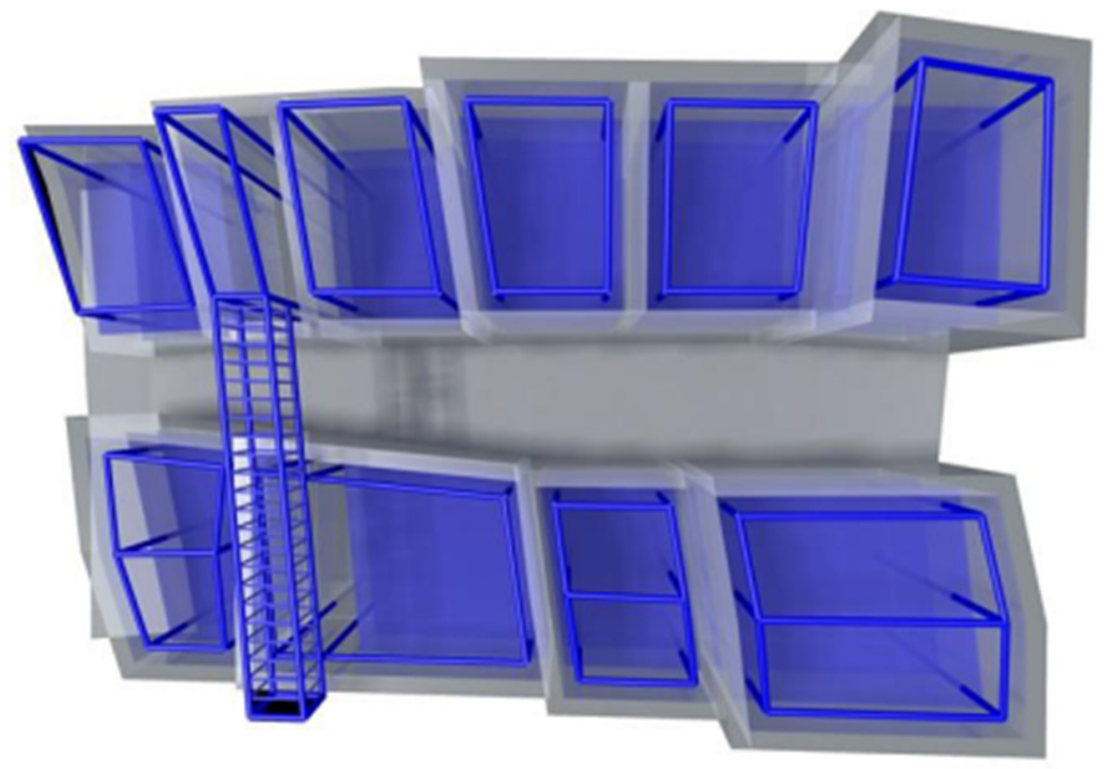

Figure 4: Top view project proposal.

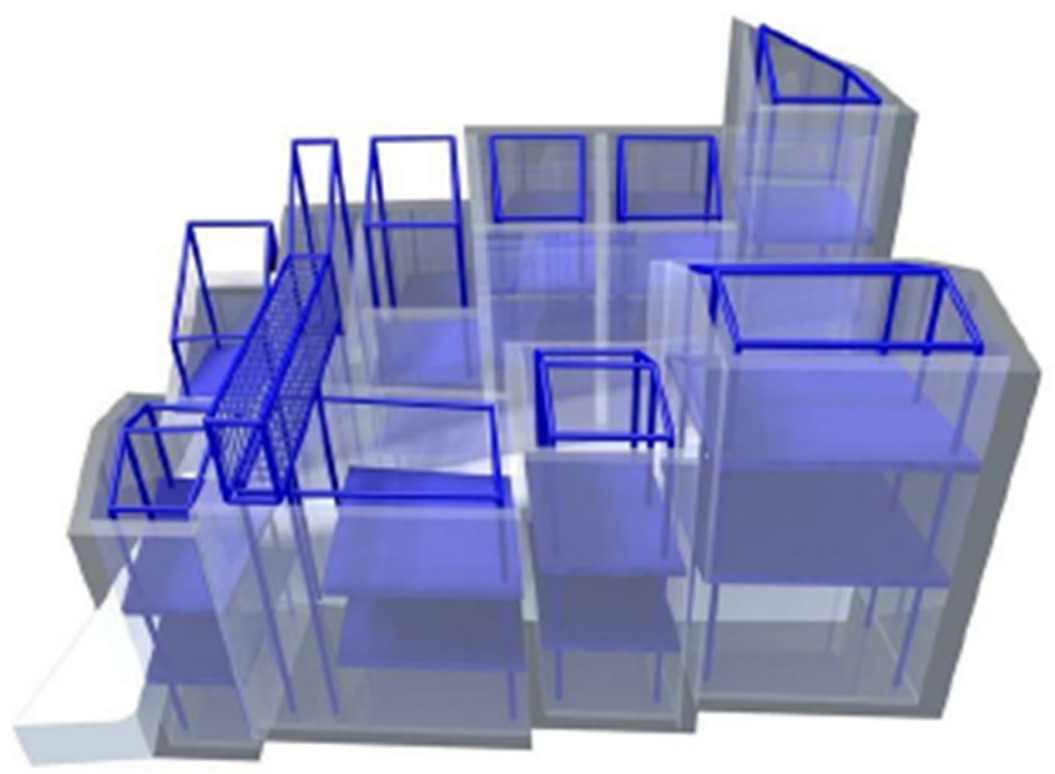

Figure 5: Perspective view project proposal. 


\section{Conclusions}

The historical contexts turn out to be fragile in many aspects because any change can alter the origin of the construction. In these settings it must intervene with a lot of attention and improvement of life must take advantage of the natural resources and reinterpreting the existing formal and constructive aspects. All this can be pursued through a compatibility verification process.

In this case, it is played the ancient conception of the arched house through a modern structure that settles perfectly into the history of the place without affecting the original structure of the building and giving a contribution to the improvement of the street ventilation and nearby places.

The research further developments are aimed at drafting a numerical control process of the results achieved by means of which occur within compatibility processes (formal and construction) the ability to integrate systems related to sustainable and to local resources:

-mini wind

-mini plumber

-integrated photovoltaic.

\section{References}

[1] Abbate E., Scritti sulla Valle Porclaneta, comune di Magliano dei Marsi, 1903.

[2] Antinori A.L., Annali, Biblioteca Provinciale dell'Aquila (ediz. Anast., Bologna, Forni), vol VIII.

[3] Centofanti M., "Struttura e forma urbana nei centri della media valle dell'Atemo“, L'Aquila, 1975.

[4] Fiorani P., Una città Romana “Magliano dei Marsi“", 1978.

[5] Salingaros N. A., Nikos A., The Laws of Architecture from a Physicist's Perspective, Physics Essays, Vol. 8, 1995.

[6] Zordan L., Le tradizioni del costruire della casa in pietra: materiali, tecniche, modelli e sperimentazioni, L' Aquila, 2002.

[7] Zordan L., Tecniche costruttiva dell'edilizia aquilana Tipi edilizi apparecchiatura costruttiva, in A-A.VV, "L'Aquila città di piazze", Pescara, 1992.

[8] Zordan, L., Lettura tipologica del costruito, metodologia critica e strumenti operativi, in "Centri antichi minori d'Abruzzo: recupero e valorizzazione", Roma, 1996.

[9] Zordan, L., Recupero e residenza, relazione introduttiva alla seconda sessione in "Atti del Convegno Internazionale La residenza in Europa alle soglie del terzo millennio“, Napoli, 1997.

[10] Zordan L., Centri Storici d'Abruzzo. Un manuale per il recupero, in "Bollettino CAI" IV serie, n. 1, giugno 1998. 